Pesq. Vet. Bras. 25(3):135-142, jul./set. 2005

\title{
Intoxicação em suínos pela ingestão de sementes de Aeschynomene indica (Leg.Papilionoideae) ${ }^{1}$
}

\author{
Fabiano N. Oliveira ${ }^{2}$, Raquel R. Rech ${ }^{2}$, Daniel R. Rissi ${ }^{2}$, Ricardo R. Barros ${ }^{2}$ e Claudio \\ S.L. Barros ${ }^{3 *}$
}

\begin{abstract}
Oliveira F.N., Rech R.R., Rissi D.R., Barros R.R., \& Barros C.S.L. 2005. [Poisoning in swine from the ingestion of Aeschynomene indica (Leg.Papilionoideae) seeds.] Intoxicação em suínos pela ingestão de sementes de Aeschynomene indica (Leg. Papilionoideae). Pesquisa Veterinária Brasileira 25(3):135-142. Depto Patologia, Universidade Federal de Santa Maria,
\end{abstract} 97105-900 Santa Maria, RS, Brazil.E-mail: claudioslbarros@uol.com.br

A spontaneous outbreak of a neurological disease in swine caused by the ingestion of Aeschynomene indica seeds and the reproduction of the disease in the same animal species are reported. The natural outbreak occurred in a pig-raising facility in the central region of the state of Rio Grande do Sul, Brazil. On the premises there were 100 pigs (20 breeding sows and 80 young weaned pigs from several categories) that were fed a ration made by mixing $50 \%$ of corn bran, $25 \%$ of soybean bran, $5 \%$ of a commercial mix of vitamins and minerals, and $20 \%$ of broken rice contaminated with $40 \%$ of $A$. indica seeds. Although all pigs apparently ingested the same ration, only 45-day-old pigs were affected; morbidity, mortality and lethality rates were respectively $25 \%$ $40 \%, 8.5 \%-20 \%$; and 25\%-66\%. Clinical signs appeared 24 hours after the beginning of feeding of $A$. indica seeds contaminated ration and included variable degrees of incoordinated gait, falls, sternal recumbency with the hind limbs in a wide base stance, lateral recumbency and death. It was not possible to ascertain how many pigs recovered nor the time frame of recovery. One pig was euthanatized and necropsied in the premises. The poisoning was reproduced in 5 young pigs (A-E) which were fed a ration containing $10 \%$ (Pig A), $15 \%$ (Pig B) and $20 \%$ (Pigs C-E) of $A$. indica seeds, and in one older pig (Pig F) which was fed a ration with $16.5 \%$ of $A$. indica seeds. Pigs A, B and F were euthanatized and Pigs C-E died of an acute disease respectively 16, 21 and 24 hours after the beginning of the experiment. Clinical signs were similar to those observed in pigs of the spontaneous outbreak. Necropsy findings included marked hyperemia of the encephalic leptomeninges of all pigs; there were large amounts of $A$. indica seeds in the stomach and reddening of the intestinal wall and bloody intestinal content in Pigs C-E. A hematoma was observed in the lungs of Pig $\mathrm{C}$. The histopathological findings in the brain of pigs fed rations with larger concentrations $(20 \%)$ of $A$. indica seeds (C-E) included congestion, edema and hemorrhage and swollen vascular endothelia with focal symmetrical distribution in several brain nuclei and in the telencephalic cortex. In Pigs A and $\mathrm{B}$, and in Pig F, the case which received the lower dosage of the seeds of $A$. indica, and in the pig from the spontaneous outbreak, histopathological changes in the brain consisted of discrete focal symmetrical areas of malacia in which closely packed Gitter cells and astrocytosis, and capillaries with swollen endothelium obliterated the normal neuropil. The symmetrical malacic foci caused by the ingestion of $A$. indica seeds in swine affected cerebellar and vestibular nuclei, putamen, and the mesencephalic oculomotor and red nuclei. This indicates that the $A$. indica seeds ingestion was responsible for the neurological condition, that it may be fatal and seems to affect equally young

\footnotetext{
${ }^{1}$ Recebido em 2 de fevereiro de 2005.

Aceito para publicação em 7 de março de 2005.

Realizado com apoio financeiro do Programa de Apoio a Núcleos de Excelência (PRONEX), Proc. CNPq 7697102600. Parte da Dissertação de Mestrado do primeiro autor.
}

\footnotetext{
2 Programa de Pós-Graduação em Medicina Veterinária, área de concentração em Patologia Veterinária, Centro de Ciências Rurais, Universidade Federal de Santa Maria (UFSM).

${ }^{3}$ Departamento de Patologia, Laboratório de Patologia Veterinária, UFSM, 97105-900 Santa Maria, Rio Grande do Sul. *Autor para correspondência. Email: claudioslbarros@uol.com.br
} 
and older swine. The clinical outcome and pathological changes were dose-dependent, and the brain lesions progressed from damaged blood vessels to vasogenic edema, hemorrhage and malacia.

INDEX TERMS: Poisonous plants, plant poisoning, Aeschynomene indica, Leguminosae Papilionoideae, pathology, diseases of the central nervous system, diseases of swine.

RESUMO.- Relata-se um surto espontâneo de intoxicação em suínos pela ingestão de sementes de Aeschynomene indica e a reprodução da doença nessa espécie animal. O surto espontâneo ocorreu numa propriedade de criação de suínos localizada na região central do Rio Grande do Sul. Nessa propriedade havia 100 suínos (20 matrizes e 80 suínos jovens de várias categorias). Os suínos eram alimentados com uma ração feita na propriedade pela mistura de $50 \%$ farelo de milho, $25 \%$ de farelo de soja, $5 \%$ de um suplemento vitamínico-mineral de origem comercial e $20 \%$ quirera de arroz contaminada por $40 \%$ de sementes de $A$. indica. Embora aparentemente todos os suínos tenham recebido a mesma ração, apenas os suínos de 45 dias de idade foram afetados; as taxas de morbidade, mortalidade e letalidade foram respectivamente $25 \%$ $40 \%, 8,5 \%-20 \%$ e $25 \%-66 \%$. Os sinais clínicos apareceram cerca de 24 horas após o início da administração da ração contendo sementes de $A$. indica e incluíam vários graus de incoordenação no andar, quedas, decúbito esternal com membros pélvicos posicionados afastados entre si, decúbito lateral e morte. Não foi possível determinar quantos suínos se recuperaram e quanto tempo levou a recuperação. Um suíno foi submetido à eutanásia $\mathrm{e}$ necropsiado na propriedade. A doença foi reproduzida em 5 suínos jovens (A-E) alimentados com uma ração contendo 10\%(Suíno A), $15 \%$ (Suíno B) e 20\% (Suínos C-E) de sementes de A. indica e em um suíno mais velho (Suíno F) que recebeu uma ração com 16,5\% de sementes de $A$. indica. Os sinais clínicos foram semelhantes aos observados nos suínos do surto espontâneo. Os Suínos A, B e F foram submetidos à eutanásia e os Suínos C-E morreram de uma doença aguda respectivamente 16, 21 e 24 horas após o início do experimento. Os achados de necropsia incluíam acentuada hiperemia das leptomeninges em todos os suínos, grandes quantidades de sementes de $A$. indica no estômago e avermelhamento transmural da parede do intestino e conteúdo intestinal sanguinolento nos Suínos C-E. Um hematoma foi observado no pulmão do Suíno C. Os achados histopatológicos no encéfalo dos suínos alimentados com as maiores concentrações (20\%) de sementes de A. indica (C-E) consistiram em áreas focais e simétricas de congestão, edema, hemorragia e tumefação do endotélio vascular em diversos núcleos e no córtex telencefálico. Nos Suínos A e B, que receberam menores concentrações das sementes de $A$. indica, $\mathrm{e}$ no Suíno F, caso espontâneo da doença, as alterações histológicas no encéfalo consistiam de áreas bem definidas de malacia focal simétrica; nessas áreas a neurópila normal era obliterada por numerosos macrófagos espumosos dispostos em estreita aposição, astrocitose e capilares com endotélios tumefeitos. Os focos de malacia focal simétrica em suínos intoxicados com sementes de $A$. indica afetavam os núcleos cerebelares e vestibulares, a substância negra, o putâmen e os núcleos mesencefálicos, oculomotor e núcleo vermelho. Esses dados indicam que a ingestão de sementes de $A$. indica é responsável por essa condição neurológica, que a doença pode ser fatal e que parece afetar igualmente suínos jovens e adultos. $\mathrm{O}$ desenlace clínico e as alterações patológicas são dependentes da dose e as lesões encefálicas progridem de danos vasculares a edema vasogênico, hemorragia e malacia.

TERMOS DE INDEXAÇÃO: Plantas tóxicas, intoxicação por plantas, Aeschynomene indica, Leguminosae Papilionoideae, patologia, doenças do sistema nervoso central, doenças de suínos.

\section{INTRODUÇÃO}

Aeschynomene indica L. (Leguminosae Papilionoideae) é uma planta encontrada principalmente na Índia e Malásia e, com menor freqüêencia, na Austrália, ilhas do Pacífico, África e costa sul dos Estados Unidos. No Brasil, é descrita como inço de lavouras de arroz irrigadas no Rio Grande do Sul e conhecida pelo nome popular de “angiquinho" (Kissmann \& Groth 1997). As épocas da produção de sementes pelo arroz e por $A$. indica coincidem e as sementes das duas plantas podem ser colhidas juntas. No processamento do arroz, as sementes de $A$. indica são refugadas junto com a quirera (grãos de arroz quebrados), um subproduto largamente utilizado na alimentação de suínos no Rio Grande do Sul.

Uma condição neurológica associada ao consumo de quirera de arroz contaminada por sementes de $A$. indica e caracterizada por degeneração focal simétrica nos núcleos cerebelares e vestibulares foi descrita em suínos jovens no Rio Grande do Sul (Timm 1996, Riet-Correa et al. 2003); embora os distúrbios neurológicos e as lesões encefálicas fossem marcantes, todos os suínos afetados se recuperaram, levando à impressão que a intoxicação era auto-limitante, terminando sem mortes e sem necessidade de intervenção terapêutica.

No entanto, em março de 2001, um surto espontâneo da intoxicação por sementes de $A$. indica com taxas de mortalidade altas ocorreu numa propriedade de criação de suínos localizada no município de Cachoeira do Sul, na região central do Rio Grande do Sul. Embora a população sob risco incluísse vários suínos adultos, a intoxicação afetou apenas suínos jovens (ao redor de 45 dias de idade).

O objetivo deste trabalho foi descrever mais esse surto espontâneo e reproduzir experimentalmente a doença a fim de responder às seguintes perguntas relacionadas à intoxicação por sementes de $A$. indica em suínos: (1) a intoxicação pode provocar mortalidade em suínos ou é sempre auto-limitante? (2) Os suínos adultos são resistentes à intoxicação? (Essa dúvida se originou do fato de que os poucos relatos existentes descrevem a doença apenas em suínos jovens), e (3) Qual a distribuição das lesões no encéfalo e qual sua patogênese?

\section{MATERIAL E MÉTODOS}

Dados epidemiológicos e clínicos do surto espontâneo foram obtidos junto ao proprietário de uma criação semi-industrial de suínos, situada na região central do Rio Grande do Sul. Um suíno dessa propriedade foi submetido à eutanásia e necropsiado.

Para reprodução experimental da intoxicação, seis suínos, identificados pelas letras A-F, foram alimentados com ração composta 
Quadro 1. Intoxicação pelas sementes de Aeschynomene indica em suínos. Delineamento experimental

\begin{tabular}{ccccc}
\hline Suíno & Idade & $\begin{array}{c}\text { Peso } \\
(\mathrm{kg})\end{array}$ & $\begin{array}{c}\text { Concentração de } \\
\text { sementes na ração }(\%)\end{array}$ & $\begin{array}{c}\text { Tempo de ingestão } \\
\text { (horas) }\end{array}$ \\
\hline A & 45 dias & 17 & 10 & 36 \\
B & 55 dias & 28 & 15 & 12 \\
C & 50 dias & 19 & 20 & 6 \\
D & 55 dias & 20 & 20 & 6 \\
E & 55 dias & 29 & 20 & 6 \\
F & 3 anos & 245 & 16,5 & 24
\end{tabular}

de farelo de milho misturado a diferentes proporções de quirera de arroz contaminada com sementes de Aeschynomene indica (Quadro 1). O Suíno A era macho, todos os outros eram fêmeas. Cinco suínos (A-E) eram jovens (idades entre 45 e 55 dias) e o Suíno $\mathrm{F}$ era uma porca de $245 \mathrm{~kg}$ e 3 anos de idade. A inclusão desse suíno no experimento objetivou verificar se os adultos poderiam ser resistentes aos efeitos tóxicos das sementes de $A$. indica. Além da ração, os suínos do experimento recebiam água a vontade. Todos os suínos do experimento foram necropsiados.

O encéfalo e fragmentos de figado, rim e pulmão do suíno do surto espontâneo e dos seis suínos do experimento foram fixados em formol a $10 \%$ e processados rotineiramente para histologia. $O$ encéfalo inteiro foi fixado em 1,5 litros de formol a $10 \%$ por duas semanas e então seccionado coronalmente a intervalos de $0,5 \mathrm{~cm}$ para exame macroscópico. Cinco regiões do cérebro foram consistentemente processadas para histologia: (1) bulbo na altura do obex, (2) cerebelo e pedúnculos cerebelares, (3) mesencéfalo na altura dos colículos caudais, (4) córtex parietal e tálamo e (5) córtex frontal com núcleos da base.

\section{RESULTADOS}

Na propriedade onde ocorreram os surtos espontâneos havia 100 suínos (20 matrizes e 80 suínos jovens desmamados de várias categorias). Os suínos eram alimentados com uma ração feita na propriedade pela mistura de $50 \%$ farelo de milho, $25 \%$ de farelo de soja, $5 \%$ de um suplemento vitamínico-mineral de origem comercial e $20 \%$ quirera de arroz contaminada por $40 \%$ de sementes de Aeschynomene indica (Fig. 1).

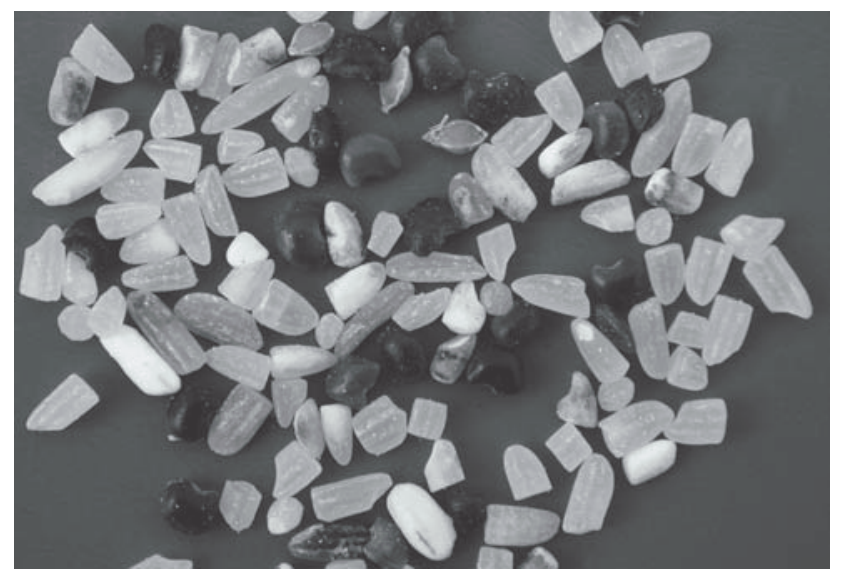

Fig. 1. Quirera de arroz contaminada com sementes de Aeschynomene indica. As sementes são pretas ou marrons, oblongas, reniformes, com 2,8x2,5mm de comprimento.
A doença foi vista somente em suínos jovens de aproximadamente 45 dias, embora todos os suínos tivessem, aparentemente, acesso à mesma ração. Em cada pocilga, onde havia 10-12 suínos dessa idade, 3-4 suínos adoeceram e 1-2 morreram, indicando taxas de morbidade, mortalidade e letalidade respectivamente de $25 \%-40 \%$; $8,5 \%-20 \%$; e $25 \%-66 \%$. Os sinais clínicos apareciam ao redor de 24 horas após o início do consumo da ração contaminada ( $\mathrm{RC}$ ) e incluíam graus variáveis de andar incoordenado e quedas que evoluíam para decúbito esternal com os membros pélvicos abertos e incapacidade de se levantar. Freqüentemente o suíno afetado assumia uma posição com a parte ventral do corpo roçando o chão e com os membros pélvicos bem afastados para facilitar a propulsão; em seguida sobrevinha decúbito lateral e a morte ocorria em média 36 horas após o início da ingestão da RC. Alguns suínos doentes se recuperaram, mas o proprietário não soube informar em quanto tempo e quantos animais se recuperaram. Lesões macroscópicas restringiam-se à acentuada hiperemia das leptomeninges.

Os suínos jovens do experimento (A-E) consumiram voluntariamente ao redor de $1 \mathrm{~kg}$ da $\mathrm{RC}$ antes de mostrar os primeiros sinais clínicos, quando então a RC era retirada e substituída por farelo de milho. Os suínos A e B foram submetidos à eutanásia respectivamente 36 e 72 horas após o início do experimento. Esses suínos entraram em decúbito esternal e permaneciam com os membros pélvicos abertos (Fig. 2), incapacitados de levantar-se 36 e 12 horas, respectivamente, após terem recebido a RC. Os Suínos C-E morreram após um quadro clínico agudo, respectivamente, 16, 21 e 24 horas após o início do experimento.

O Suíno $\mathrm{F}$ ingeriu, no primeiro dia do experimento, pela manhã, $3 \mathrm{~kg}$ de ração contaminada com $16,5 \%$ de sementes de $A$. indica ( $495 \mathrm{~g}$ de sementes de $A$. indica ou $2,02 \mathrm{~g} / \mathrm{kg}$ ). Cerca de 6 7 horas após ingerir a primeira dose da ração, mostrou inquietação, decúbito, tremores musculares leves e contínuos, porém mais acentuados no membro anterior direito, e dificuldade de levantar (Fig. 3). Nessa mesma hora, ingeriu mais $0,5 \mathrm{~kg} \mathrm{RC} \mathrm{(83,3g}$ de sementes de $A$. indica ou $0,34 \mathrm{~g} / \mathrm{kg}$ ). A partir desse momento, apresentou anorexia total, decúbito constante e piora de estado corporal. Refugava o alimento e por motivos humanitários foi submetido à eutanásia no quarto dia após o início do experimento.

Em todos os suínos do experimento observou-se acentuado avermelhamento das leptomeninges. Nos Suínos C-E, havia grande quantidade de sementes de $A$. indica não digeridas no estômago, avermelhamento transmural do intestino delgado e conteúdo intestinal sanguinolento. Um hematoma de $4 \times 4 \times 5 \mathrm{~cm}$ foi observado no lobo apical do pulmão direito do Suíno C. Na região dos núcleos cerebelares e vestibulares dos Suínos D-F, foram observadas hemorragias multifocais e simétricas em regiões correspondentes aos núcleos cerebelares ou vestibulares (Fig. 4). Achados incidentais de necropsia (pericardite fibrinosa organizada no Suíno C e filamentos de fibrina no saco pericárdico do Suíno D) ocorreram ocasionalmente.

Microscopicamente, os achados significativos restringiramse ao encéfalo. Em todos os fragmentos, confirmou-se a hiperemia das leptomeninges (Fig. 5) observada macroscopicamente. Basi- 

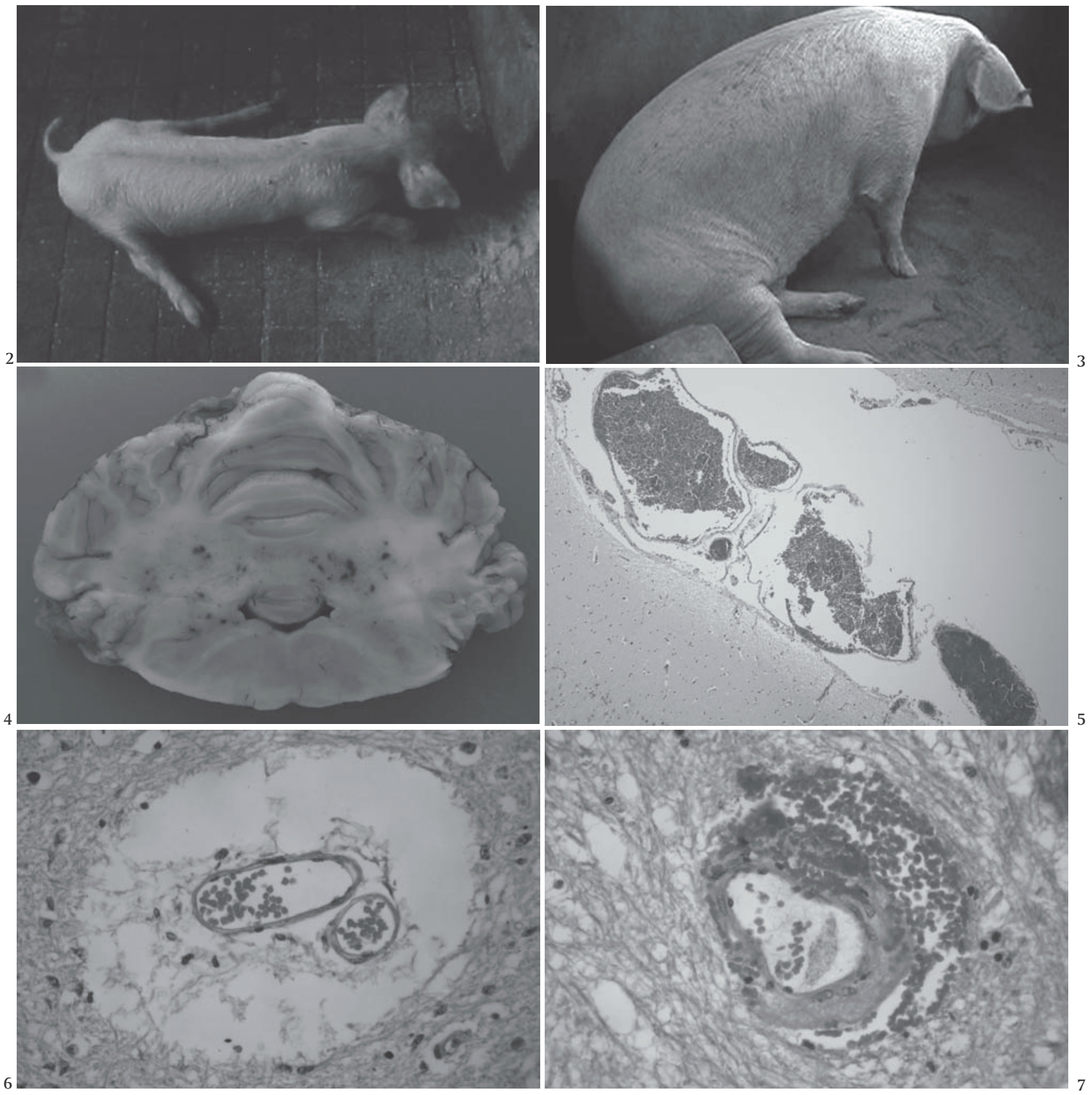

Fig. 2. Suíno A, intoxicado experimentalmente pelas sementes de Aeschynomene indica. A parte ventral do corpo roça o chão e os membros pélvicos estão bem afastados uns dos outros para facilitar a propulsão.

Fig. 4. Intoxicação experimental pelas sementes de Aeschynomene indica. Secção coronal do cerebelo passando pelos pedúnculos cerebelares e ponte (Suíno F). Focos de hemorragia podem ser observados na altura dos núcleos cerebelares fastigial, interposto e lateral; no lado esquerdo hemorragias puntiformes nas imediações dos núcleos vestibulares.

Fig. 6. Acentuado edema perivascular no Núcleo vestibular medial, na intoxicação experimental pelas sementes de Aeschynomene indica (Suíno C). HE, obj. 40.

Fig. 3. Suíno F, intoxicado experimentalmente pelas sementes de Aeschynomene indica, tem dificuldade em se levantar.

Fig. 5. Hiperemia leptomeníngea acentuada do telencéfalo, na intoxicação experimental pelas sementes de Aeschynomene indica (Suíno F). HE, obj. 20.

Fig. 7. Edema e hemorragia perivasculares no pedúnculo cerebelar, na intoxicação experimental pelas sementes de Aeschynomene indica (Suíno D). HE, obj. 40. 


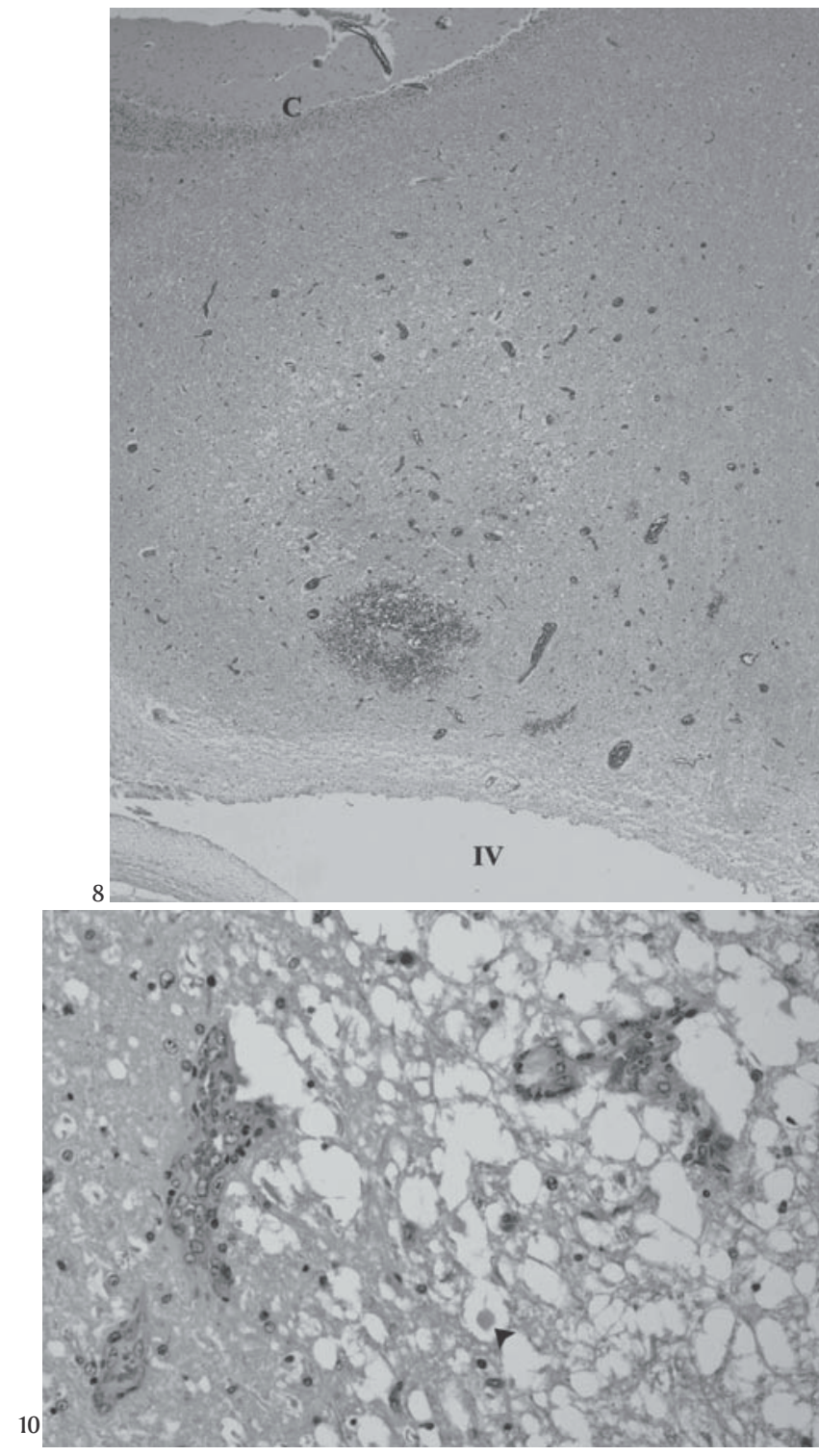

Fig. 8. Intoxicação experimental pelas sementes de Aeschynomene indica (Suíno F). Histologia da lesão mostrada na Fig. 4. Há uma área focal de edema, hemorragia e degeneração neuronal no núcleo cerebelar fastigial [o quarto ventrículo (IV) e córtex cerebelar (C) estão identificados], na intoxicação experimental pelas sementes de Aeschynomene indica (Suíno F). HE, obj. 20.

Fig. 9. Tumefação acentuada das células endoteliais e edema com rarefação da neurópila no Núcleo cerebelar (à esquerda, um neurônio encontra-se comprimido pelo edema), na intoxicação experimental pelas sementes de Aeschynomene indica (Suíno F). HE, obj. 40.

Fig. 10. Tumefação acentuada das células endoteliais em três vasos no Núcleo cerebelar; o edema da neurópila é mais extenso que o da figura anterior e há um esferóide axonal (cabeça de seta) indicando degeneração/morte de neurônios, na intoxicação experimental pelas sementes de Aeschynomene indica (Suíno F). HE, obj. 40.

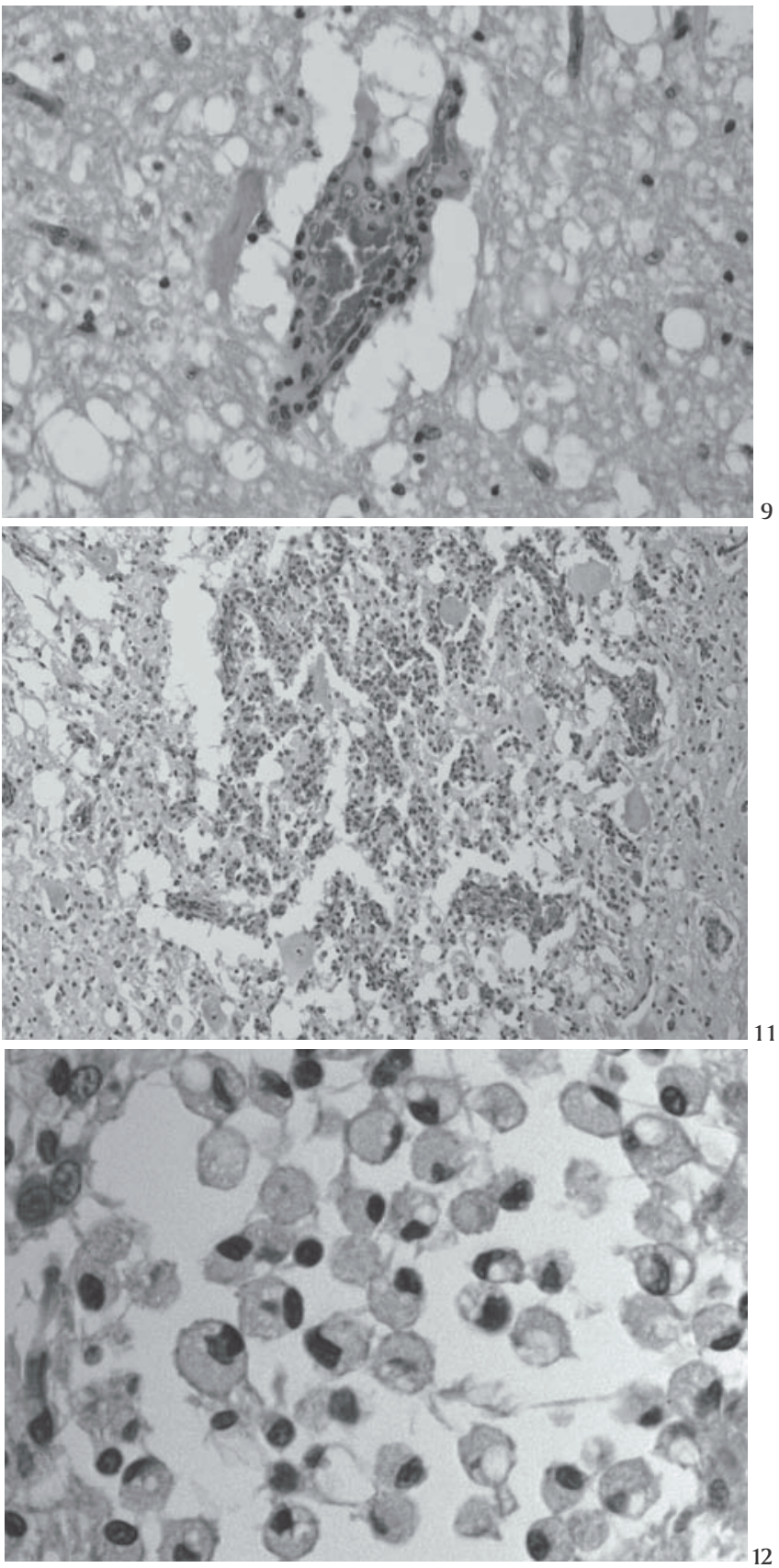

Fig. 11. Mesencéfalo, núcleo oculomotor. Um grande número de células mesodérmicas (células Gitter) afluiu para o foco de lesão e define a área de malacia através de fagocitose, na intoxicação experimental pelas sementes de Aeschynomene indica (Suíno B). HE, obj. 20.

Fig. 12. Encefalomalacia focal simétrica em suínos causada por ingestão de sementes de Aeschynomene indica (Suíno A). Foco de malacia no núcleo vestibular lateral. A arquitetura da neurópila é obliterada por agrupamentos de numerosas células Gitter e alguns vasos. HE, obj. 40. 
Quadro 2. Tipo e localização das alterações histopatológicas ${ }^{a}$ num suíno do surto espontâneo (SE) e em seis suínos intoxicados experimentalmente (A-F)

\begin{tabular}{|c|c|c|}
\hline Suíno & Tipo de lesão & Localização da lesão \\
\hline SE & Malacia focal simétrica & Núcleos cerebelares e vestibulares ${ }^{b}$ \\
\hline A & Malacia focal simétrica & Núcleos cerebelares e vestibulares \\
\hline B & Malacia focal simétrica & $\begin{array}{l}\text { Núcleos cerebelares e vestibulares, núcleo oculomotor, nú- } \\
\text { cleo vermelho, putâmen }\end{array}$ \\
\hline $\mathrm{C}$ & Congestão, edema perineuronal e perivascular, $\mathrm{TNCEs}^{\mathrm{c}}$ & $\begin{array}{l}\text { Núcleos cerebelares e vestibulares, substância negra, córtex } \\
\text { telencefálico, núcleos da base, cápsula interna }\end{array}$ \\
\hline $\mathrm{D}$ & $\begin{array}{l}\text { Congestão, edema perineuronal e perivascular, TNCEs, } \\
\text { hemorragia perivascular bilateral simétrica acentuada. }\end{array}$ & $\begin{array}{l}\text { Núcleos cerebelares e vestibulares, córtex telencefálico, nú- } \\
\text { cleos da base, cápsula interna }\end{array}$ \\
\hline $\mathrm{E}$ & Congestão, edema perineuronal e perivascular, TNCEs, & Núcleos cerebelares e vestibulares, trato vestibular espinhal \\
\hline
\end{tabular}

Núcleos cerebelares e vestibulares

F Hemorragia perivascular bilateral simétrica associada a TNCEs edema perivascular e perineuronal, congestão e hemorragia submeníngea. Congestão, edema perineuronal e perivascular. Distensão da bainha de mielina, esferóides axonais

\footnotetext{
aTodos os suínos apresentavam congestão acentuada das leptomeninges.

bos núcleos cerebelares mencionados na tabela incluem os núcleos fastigial, interposto e lateral; os núcleos vestibulares incluem os núcleos vestibular medial e vestibular lateral.

${ }^{\mathrm{c}}$ TNCEs $=$ tumefação do núcleo das células endoteliais.
}

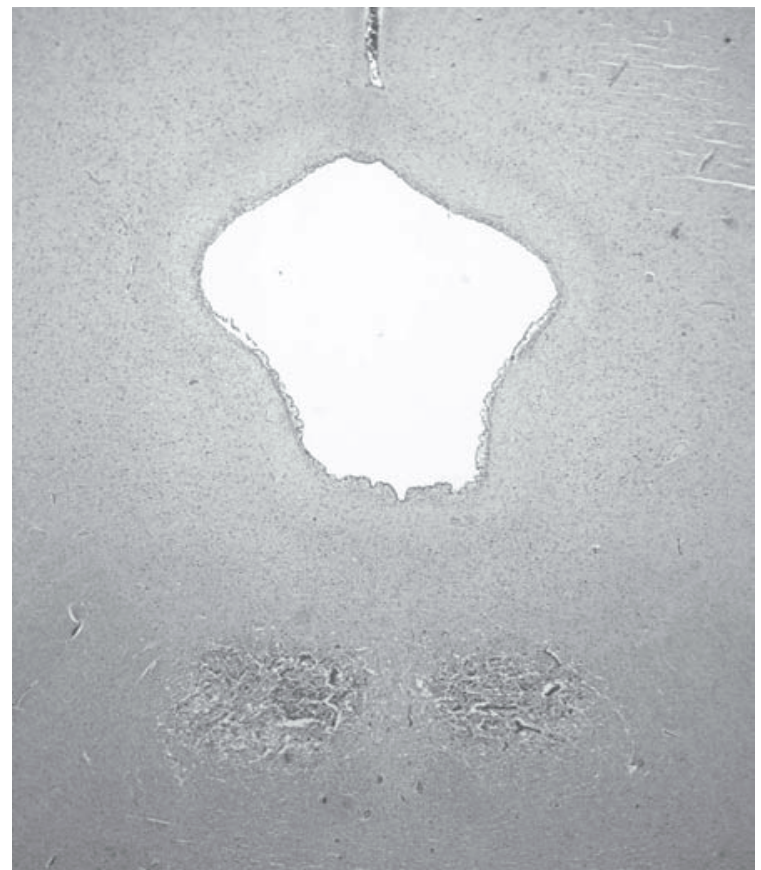

Fig. 13. Encefalomalacia focal simétrica em suínos causada por ingestão de sementes de Aeschynomene indica (Suíno B). Menor aumento mostrando dos focos de malacia bilaterais e simétricos no núcleo oculomotor do mesencéfalo. HE, obj. 2,5.

camente, os achados histológicos foram classificados como distúrbios circulatórios, incluindo hiperemia, edema (Fig. 6) e hemorragia (Fig. 7 e 8). Essas lesões eram quase sempre acompanhadas de tumefação do endotélio dos vasos (Fig. 9), que pareciam apresentar aumento da permeabilidade associada a edema e hemorragia. Essas lesões eram focais e de intensidade variável. Além do edema, nas lesões mais avançadas, observou-se distensão da bainha de mielina e esferóides axonais em meio à lesão (Fig 10). Esse tipo de alteração mais aguda foi observada nos suínos C-F e afetava os núcleos cerebelares (fastigial, interposto e lateral), os núcleos vestibulares (medial e lateral), a substância negra, os núcleos da base e a cápsula interna, o trato vestibular espinhal e o córtex telencefálico (Quadro 2).

As lesões microscópicas encontradas no suíno afetado espontaneamente na propriedade e nos suínos A e B do experimento foram idênticas quanto ao tipo e estadiamento. Essas lesões eram menos agudas que as descritas anteriormente (Suínos C-F) e consistiam de focos de malacia bem definidos e simétricos, onde a neurópila era substituída por aglomerados de macrófagos espumosos em estreita aposição, esferóides axonais e áreas de desmielinização com câmaras de digestão. Nessas áreas havia desaparecimento de neurônios e astrocitose. Tipicamente, no interior das áreas de necrose e na sua periferia, os vasos exibiam tumefação dos núcleos das células endoteliais (Fig. 11 e 12). Áreas de malacia como as descritas acima tinham distribuição multifocal e bilateralmente simétrica e foram observadas nos núcleos cerebelares fastigial, interposto e lateral e nos núcleos vestibulares medial e lateral nos Suínos A, B e no suíno do surto espontâneo, e nos núcleos mesencefálicos oculomotor (Fig 13) e núcleo vermelho e no putâmen no Suíno B (Quadro 2).

\section{DISCUSSÃO}

O diagnóstico de intoxicação por Aeschynomene indica neste estudo foi confirmado pelos dados epidemiológicos, sinais clínicos, achados patológicos, pela presença das sementes contaminantes na quirera de arroz e pela reprodução experimental da doença através da alimentação de suínos com ração contaminada (RC) por sementes de $A$. indica.

Na descrição original dessa forma de intoxicação (Timm 1996, Riet-Correa et al. 2003) relata-se que, dos suínos que ingeriram $3 \%, 6 \%$, e $13 \%$ de RC por sementes de $A$. indica, somente os do último grupo adoeceram e todos os suínos afetados se recupe- 
raram. No surto deste relato, no entanto, ocorreram taxas de mortalidade e letalidade respectivamente de $8,5 \%-20 \%$ e $25 \%$ $66 \%$. Essa diferença nas observações pode estar relacionada à dose das sementes tóxicas na ração. Neste estudo, a ingestão de RC com $20 \%$ sementes de $A$. indica foram fatais para suínos, mas não com RC com $10 \%, 15 \%$ e $16,5 \%$ dessas sementes. Os três suínos que morreram ingeriram a RC com $20 \%$ sementes de $A$. indica voluntária e rapidamente, o que pode perfeitamente ocorrer em situações de intoxicação acidental e portanto, a ocorrência de surtos espontâneos desta intoxicação com mortalidade alta talvez seja mais comum do que se pensava até aqui.

Neste estudo, o consumo de aproximadamente $1 \mathrm{~kg}$ de RC com $20 \%$ de sementes de $A$. indica causou a morte de 3 suínos com 19, 20 e $29 \mathrm{~kg}$ de peso corporal. Isso indica uma dose letal entre 6,6 e $10 \mathrm{~g} / \mathrm{kg}$. Esses suínos consumiram menor quantidade de sementes por dia do que suínos de um experimento anterior (Riet-Correa et al. 2003), que consumiram um total de $20 \mathrm{~g} / \mathrm{kg}$ de sementes de $A$. indica, porém ao longo de 6 dias (média de 3,3 g/ $\mathrm{kg} / \mathrm{dia}$ ); como já havia sido notado (Riet-Correa et al. 2003), suínos que ingerem a RC sofregamente, desenvolvem os sinais clínicos em menos tempo.

A julgar pela informação fornecida pelo proprietário, os suínos afetados na propriedade descrita neste relato recebiam uma RC com $8 \%$ de sementes de $A$. indica; como os suínos afetados tinham ao redor de 45 dias, estima-se que tivessem cerca de 10 $15 \mathrm{~kg}$. Se esses suínos ingerissem de 500 a $1000 \mathrm{~g}$ de RC por dia - o que é estimado para suínos dessa faixa etária e peso (Driemeier 2004), teriam ingerido entre 4 e $8 \mathrm{~g} / \mathrm{kg} / \mathrm{dia}$ de sementes. Portanto, suínos dessa propriedade que tivessem ingerido sofregamente um $\mathrm{kg}$ da RC contaminada em um dia poderiam ter desenvolvido a doença com desenlace fatal, uma vez que teriam ingerido acima da dose tóxica letal.

O consumo de sementes de $A$. indica causou lesões nos núcleos cerebelares e vestibulares, como já havia sido descrito (RietCorrea et al. 2003), mas adicionalmente ocorreram lesões simétricas de malacia em outras regiões específicas do encéfalo como núcleos da base e núcleos mesencefálicos. Sugere-se assim, que a denominação "encefalomalacia focal simétrica em suínos causada por planta tóxica" seja mais adequada para descrever a enfermidade.

O princípio ativo de $A$. indica não foi ainda determinado, mas experimentos realizados com a administração de várias frações químicas de sementes da planta a camundongos indicaram que o princípio ativo está no resíduo etil-acetato e que camundongos podem ser usados para testar os efeitos tóxicos das sementes de $A$. indica (Haraguchi et al. 2003). As alterações histológicas observadas nos suínos afetados indicam que o princípio ativo das sementes de $A$. indica seja uma angiotoxina que causa lesão às células do revestimento vascular (endotélio). Isso é sugerido pela tumefação endotelial, edema e hemorragia que ocorrem nos casos mais agudos. Uma patogênese semelhante é descrita para a doença do edema de suínos (Kurtz et al. 1969, Clugston et al. 1974, Francis et al. 1989) e para a encefalomalacia focal simétrica dos cordeiros (Buxton et al. 1978). No primeiro caso, a angiotoxina é uma substância produzida por certas cepas ßhemolíticas de Escherichia coli, conhecida como princípio da doença do edema, "toxina shiga-símile" variante tipo II ou SLT-IIv
(MacLeod et al. 1991, Francis et al. 1989, Imberechts et al. 1992). No segundo caso, encefalomalacia focal simétrica (EFS), a causa é uma substância angiotóxica, a toxina épsilon, produzida por Clostridium perfringens tipo D (Finnie 1984). A semelhança entre as lesões e a provável patogênese dessas duas doenças e da intoxicação por sementes de $A$. indica em suínos são notavelmente semelhantes: as lesões causadas por doses altas produzem uma morte rápida com lesões vasculares agudas (edema e hemorragia); animais que recebem doses subletais ou que permitam uma sobrevida maior, desenvolvem focos de malacia no encéfalo. Na enterotoxemia clássica pela toxina de $C$. perfringens tipo D, o curso clínico é agudo ou superagudo, a toxina é abundante no intestino e as lesões encefálicas são, na maioria das vezes, microscópicas, mas obedecem a uma distribuição semelhante às encontradas no EFS; nessa última condição as lesões cerebrais podem ser observadas macroscopicamente como focos bilaterais e simétricos de malacia localizados na cápsula interna e nos núcleos basais adjacentes, no tálamo, no mesencéfalo e nos pedúnculos cerebelares (Buxton et al. 1978, Summers et al. 1995, Storts 1998). De forma semelhante, na doença aguda fatal em suínos intoxicados por sementes de $A$. indica, as lesões microscópicas circulatórias como hiperemia, edema e hemorragia, mas os animais que sobrevivem desenvolvem focos de malacia simétricos e bilaterais.

Desse modo, é proposto que a patogênese da intoxicação por A. indica inicia por lesão vascular com tumefação de células endoteliais, edema vasogênico (aumento da permeabilidade) e hemorragia. Com o passar do tempo, essa lesão evolui para distensão da bainha de mielina e morte neuronal por hipóxia. Os monócitos do sangue e a micróglia residente fagocitam o tecido necrótico formando um número grande de células "Gitter," que caracteriza os focos de necrose. A susceptibilidade de certos locais do cérebro para malacia é bastante conhecida (Innes \& Saunders 1962, Storts 1998, Summers et al. 1995).

Além das duas doenças acima mencionadas, lesões de necrose focal simétrica em áreas específicas do encéfalo, como as descrita nos casos deste relato, ocorrem em outras doenças de animais de produção associadas a intoxicações e toxinfecções. A ingestão de plantas do gênero Centaurea causa necrose do globo pálido e substância negra em eqüinos (Cordy 1978) e a intoxicação por selênio causa, em suínos, malacia focal simétrica da substância cinzenta dos cornos ventrais nas intumescências cervical e lombar da medula espinhal (Harrison et al. 1983, Casteel et al. 1985).

No surto espontâneo da intoxicação por sementes de $A$. indica em suínos deste relato e nos primeiros relatos dessa condição (Timm 1996, Riet-Correa et al. 2003) apenas animais jovens (ao redor de 45 dias de idade) foram afetados. Toxinfecções que produzem lesões degenerativas no encéfalo com morfologia e patogenia semelhantes às produzidas pela intoxicação por sementes de $A$. indica em suínos, como é o caso da doença do edema em suínos (Imberechts et al. 1992) e da EFS dos cordeiros (Buxton et al. 1978), afetam também animais jovens. Isso nos levou a supor que suínos adultos pudessem ser resistentes à intoxicação. $\mathrm{O}$ animal adulto (uma fêmea de 3 anos) incluído neste experimento mostrou sinais clínicos e lesões comparáveis às dos animais jovens, após ter ingerido cerca de $2,3 \mathrm{~g} / \mathrm{kg} /$ peso 
corporal. Isso sugere que suínos adultos são igualmente susceptíveis à intoxicação. É incerto se esse suíno teria se recuperado caso não tivesse sido submetido à eutanásia, mas no momento da eutanásia, estava em decúbito e não se alimentava mais.

É interessante notar que a intoxicação por selênio, que causa somente lesões na medula espinhal, apresenta sinais clínicos muito semelhantes aos da intoxicação por sementes de $A$. indica, o que deve ser de interesse para o diagnóstico diferencial, uma vez que o exame neurológico detalhado em suínos é bastante difícil.

A velocidade com que se desenvolvem os focos de malacia na intoxicação por sementes de $A$. indica em suínos é também incomum. Tradicionalmente é aceito que estágios bem desenvolvidos de malacia ocorram por volta de duas semanas ou mais após o insulto (Innes \& Saunders 1962, Storts 1998). No entanto, os Suínos A e B foram submetidos à eutanásia respectivamente 36 e 72 horas após o início do experimento e mostravam áreas de malacia completamente desenvolvidas.

Todos os sete suínos necropsiados neste estudo mostravam acentuada hiperemia das leptomeninges, indicando que isso não é uma lesão fortuita e que deve ser útil na formulação do diagnóstico, quando considerada junto com outros fatores.

\section{REFERÊNCIAS}

Buxton D., Linklater K.A. \& Dyson D.A. 1978. Pulpy kidney disease and its diagnosis by histological examination. Vet. Rec. 102:241.

Casteel S.W., Osweiler G.D., Cook W.O., Daniels G. \& Kadlec R. 1985 Selenium toxicosis in swine. J. Am. Vet. Med. Assoc. 186:1084-1085.

Clugston R.E., Nielsen N.O. \& Smith D.L.T. 1974. Experimental edema disease of swine (E. coli enterotoxemia): III. Pathology and pathogenesis. Can. J. Comp. Med. 38:34-43.

Cordy D.R. 1978. Centaurea species and equine nigropallidal encephalomalacia, p.327-336. In: Keeler R.F., Van Kampen K.R. \& James L.F. (ed.) Effects of Poisonous Plants on Livestock. Academic Press, New York. 600p.

Driemeier D. 2004. Comunicação Pessoal (Depto Patologia Clínica Veteri- nária, Setor de Patologia Clínica Veterinária, Fac.Veterinária, UFRGS, Av. Bento Gonçalves 9090, Cx. Postal 15094. Porto Alegre, RS 91540-000. E-mail: davetpat@ufrgs.br).

Finnie J.W. 1984. Histopathological changes in the brain of mice given Clostridium perfringens type D epsilon toxin. J. Comp. Pathol. 94:363370.

Francis D.H., Moxley R.A. \& Andraos C.Y. 1989. Edema disease-like brain lesions in gnotobiotic piglets infected with Escherichia coli serotype 0157:H7. Infect. Immun. 57:1339-1342.

Haraguchi M., Górniak S.L., Bailardi C.E.G. \& Riet-Correa F. 2003. Neurotoxicity to pigs and rodents from different fractions of Aeschynomene indica seeds. Vet. Human Toxicol. 45:177-179.

Harrison L.H., Colvin B.M., Stuart B.P., Sangster L.T, Gorgacz E.J. \& Gosser H.S. 1983. Paralysis in swine due to focal symmetrical poliomalacia: possible selenium toxicosis. Vet. Pathol. 20:265-273.

Imberechts H., De Greve H. \& Lintermans P. 1992. The pathogenesis of edema disease in pigs. A review. Vet. Microbiol. 31:221-233.

Innes J.R.M. \& Saunders L.Z. 1962. Encephalomalacia and myelomalacia, p.607-609. In: Ibid (ed.) Comparative Neuropathology. Academic Press, New York. 839p.

Kissmann K.G. \& Groth D. 1997. Plantas Infestantes e Nocivas, p.683-685. BASF Brasileira S.A., São Paulo. 825p.

Kurtz H.J., Bergeland M.E. \& Barnes D.M. 1969. Pathologic changes in edema disease of swine. Am. J. Vet. Res. 30:791-806

MacLeod D.L., Gyles C.L. \& Wilcock B.P. 1991. Reproduction of edema disease of swine with purified Shiga-like toxin-II variant. Vet. Pathol. 28:66-67.

Riet-Correa F., Timm C.D., Barros S.S. \& Summers B.A. 2003. Symmetric focal degeneration in the cerebellar and vestibular nuclei in swine caused by ingestion of Aeschynomene indica seeds. Vet. Pathol. 40:311-316.

Storts R.W. 1998. O sistema nervoso, p.353-416. In: McGavin M.D. \& Carlton W.W. (ed.) Patologia Especial de Thomson. $2^{\text {a }}$ ed. ArtMed, Porto Alegre. 672p.

Summers B.A., Cummings J.F. \& de Lahunta A. 1995. Degenerative diseases of the central nervous system, p.208-350. In: Ibid (ed.) Veterinary Neuropathology. Mosby, St. Louis. 527p.

Timm C.D. 1996. Intoxicação por Aeschynomene sp em suínos. Tese de Mestrado. Universidade Federal de Pelotas. 27p. 